\title{
Construction, operation, and maintenance of rubber dams
}

\author{
X.Q. Zhang, P.W.M. Tam, and W. Zheng
}

\begin{abstract}
Rubber dams are inflatable and deflatable hydraulic structures. Thousands of rubber dams have been installed worldwide for various purposes: irrigation, water supply, power generation, tidal barrier, flood control, environmental improvement, and recreation. Furthermore, rubber dams have been used in cold areas where the temperature is as low as $-40^{\circ} \mathrm{C}$. The simplicity and flexibility of the rubber dam structure and its proven reliability are key considerations in its wide scope of applications. Based on the management practices of 20 rubber dams in Hong Kong in the past 35 years, interviews with rubber dam experts and practitioners, and the investigation to the construction of a recent rubber dam, this paper provides a detailed discussion on various issues related to the construction, operation, maintenance, and repair of rubber dams.
\end{abstract}

Key words: construction, hydraulic structure, maintenance, operation, repair, rubber dam.

Résumé : Les barrages en caoutchouc sont des structures hydrauliques gonflables et dégonflables. Des milliers de barrages en caoutchouc ont été installés à travers le monde avec différents buts : irrigation, approvisionnement en eau, production d'électricité, coupe-marée, contrôle des inondations, améliorations environementales et loisirs. De plus, les barrages en caoutchouc ont été utilisés dans des régions froides où la température est aussi basse que $-40^{\circ} \mathrm{C}$. La simplicité et la flexibilité du barrage en caoutchouc et sa fiabilité prouvée sont des considérations clés dans son vaste champ d'utilisation. Cet article donne une discussion détaillée sur différentes questions reliées à la construction, l'opération, le maintient et la réparation des barrages en caoutchouc, celle-ci basée sur les pratiques de gestion de 20 barrages en caoutchouc à Hong Kong durant les 35 dernières années, sur des entretiens avec des experts et des praticiens en barrage en caoutchouc, ainsi que sur l'investigation de la construction d'un récent barrage.

Mots clés : construction, structure hydraulique, maintient, opération, réparation, barrage en caoutchouc.

[Traduit par la Rédaction]

\section{Introduction}

Rubber dams were developed in the 1950s and the first one was installed on the Los Angeles River, California, for the purpose of groundwater recharge and flood mitigation. This early dam was inflated with a combination of water and air (Plaut et al. 1998; Kahl and Ruell 1989). Since then, rubber dams have experienced continuous technological improvement. Simplicity of the rubber dam concept, flexibility, and proven reliability are key considerations in the use of rubber dams for multiple purposes. To date, thousands of rubber dams have been installed in different parts of the world, serving various functions such as irrigation, water

Received 18 June 2001. Revision accepted 21 February 2002.

Published on the NRC Research Press Web site at

http://cjce.nrc.ca on 30 May 2002.

X.Q. Zhang. ${ }^{1,2}$ Department of Civil Engineering, The

University of Hong Kong, Hong Kong, China.

P.W.M. Tam. Parsons Brinckerhoff (Asia) Ltd., Hong Kong, China.

W. Zheng. Guangdong Institute of Water Conservancy and Hydropower, Guangzhou, China.

Written discussion of this article is welcomed and will be received by the Editor until 31 October 2002.

${ }^{1}$ Corresponding author (e-mail: eagle_xqzhang@hotmail.com). ${ }^{2}$ Present address: 2861 Revelstoke Court, Vancouver, BC V6T $1 \mathrm{~N} 8$, Canada. supply, power generation, tidal barrier, water treatment, flood control, environment improvement, and recreation.

As an innovative hydraulic structure, the rubber dam project mainly consists of four parts: (i) a rubberized fabric dam body; (ii) a concrete foundation; (iii) a control room housing mechanical and electrical equipment, such as air blower/water pump, automatic inflation and deflation mechanisms; and (iv) an inlet/outlet piping system. The dam body is fixed onto the concrete foundation and abutments by a single-line or double-line anchoring system.

A unique characteristic of the rubber dam is its ability to function as a reliable crest-adjustable water gate. When inflated by a medium (air, water, or combination of both), it rises to retain water. When deflated by releasing the medium, it collapses flatly down to the foundation, completely opening the channel for free flow of water. The rubber dam can also be adjusted to operate at intermediate heights to meet the needs for different upstream and downstream water levels at different time. Air is used more often than water as the filling medium for the following reasons (Bridgestone 1994):

1. Water and water-borne debris can corrode and clog pipes.

2. The design and construction of air-filled dams are simpler.

3. Water-filled dams require a more complex piping system and often need a pond to store water for filling the dams when river water levels are low. 
4. The inflation or deflation time of an air-filled dam is much shorter than that of a water-filled dam of the same size.

5. Because of the weight of water, a water-filled dam has a squat shape, requiring more rubber material than an airfilled dam of the same height.

6. The circumference of a water-filled dam is about 4.8 times of its height, compared with 3.5 times for an airfilled dam. To accommodate the dam body, the foundation of a water-filled dam must be wider than that of an air-filled dam of the same height.

However, air-filled dams are less stable and suffer more from vibration than water-filled dams, which are preferable when hydraulic conditions are more demanding (Markus et al. 1995).

\section{Research methodology}

In this paper, a thorough review of the limited literature on rubber dams is carried out. This is followed by extensive investigations on the construction, operation, maintenance, and repair of the 20 rubber dams that have been installed in Hong Kong. At the same time, interviews/correspondences with experts and practitioners in the management of rubber dams (especially those from the Agriculture and Fisheries Department, Drainage Service Department, and Water Supply Department of Hong Kong, China) and professionals from rubber dam manufacturers are conducted. In addition, a number of field trips to some dam sites and the different phases in the construction of a new rubber dam in Hong Kong have been made.

\section{Rubber dam construction}

\section{Selection of dam site}

In the selection of a suitable dam site, geological, geomorphic, hydrological, meteorological, and hydraulic factors as well as construction methods should be taken into consideration. Although the body of a rubber dam is light and the load is uniform, the dam site should always be on a solid ground and a concrete foundation should be placed. When a rubber dam is installed on a high sediment-laden river, to avoid silt deposition closely behind the dam, the dam site should not be on a section where the longitudinal gradient abruptly becomes gentle. The dam foundation level should be higher than that of the downstream riverbed to prevent silt and gravel from getting directly under the dam body and increasing abrasion. Usually, the dam foundation is connected to the downstream riverbed by a slope of 1:4$1: 2$ (vertical:horizontal).

The dam site should be in a straight river section where the river flow is smooth and the riverbed and bank slopes are stable. The site should not be in a section where the hydraulic conditions can change abruptly. Adverse hydraulic conditions are the major cause of vibration of rubber dams. Vibration causes abrasion and tear of the dam body and can severely damage it. As a result of inappropriate dam site selection, some rubber dams have been unable to function properly and have had to be demolished. The Mahuang Weir Rubber Dam in the middle section of the Jiangan River in
China was an example of unsuitable dam site selection that has led to final failure of the rubber dam. The dam was installed in the lower part of a curved section in March 1967. The dam body, made from canvas and chloroprene rubber, measured $2.5 \mathrm{~m}$ high and $33 \mathrm{~m}$ long and used a single line anchoring system. Owing to the effect of the curved section of the river, river flows were deflected upstream of the dam. The deflected flows caused strong vibration of the dam body. In 1968, the dam body was inspected and repaired. More than 20 abraded areas were found on the dam body, with some of those areas measuring about $400 \mathrm{~cm}^{2}$ and the canvas exposed. Because flows were deflected to the left bank, abrasions on the left dam body near the bending left bank were the most serious. Many inspections and repairs were carried out in 1970, 1972, and 1973. Finally, the dam had to be demolished because of vibration damages.

\section{Construction of civil works}

The construction of river works is generally carried out in the dry season, as conditions prevailing during the wet season are not favorable for such work. To facilitate the excavation of earthworks and the construction of the dam foundation, river diversion is made. The sequence and program of works should be carefully planned. An ideal measure is to use existing channel to divert river water into adjacent lakes or ponds. If such ideal conditions do not exist, a temporary cofferdam is built to divert water downstream of the dam site. River diversion can also be realized by placing earthfill upstream of the dam site and installing a water pipe under the earthfill. River water bypasses the dam site through the water pipe into the downstream section. In addition, in a broad river, the construction of the dam foundation can begin from one side of the river by diverting water to the other side. Upon completion of the dam foundation on one side, part of the dam body can be placed on the completed dam foundation. Then, river water is diverted into this side so that construction of the dam foundation on the other side can begin. Figure 1 shows the construction site of a new rubber dam in Hong Kong, where river water flows over the dam body placed on the completed dam foundation on one side of the river (while construction of the dam foundation on the other side is in progress).

Before the placement of the dam foundation, loose material should be removed so that it is placed on sound founding material. Foundation settlement affects the crest level of the rubber dam, which is an important parameter affecting the proper functioning of the dam. In addition, reinforced concrete is used to avoid possible differential settlement that could cause tearing of the dam body. A loading test or other testing methods should be used to check the bearing force of the dam foundation. A smooth foundation surface is desirable for reducing abrasion of the dam body when it vibrates and rubs itself against the foundation. The anchoring bolts should be accurately positioned to ensure level placement of the dam body. Otherwise, improperly formed bolts may have a disastrous impact on the whole rubber dam project.

A strong and durable concrete bedplate and apron are installed to prevent wash-cut damage to the riverbed and banks by water flows. In addition, the accumulation of sediment on top of, or adjacent to, the dam will not only adversely affect 
Fig. 1. Water flowing over fixed rubber dam body.

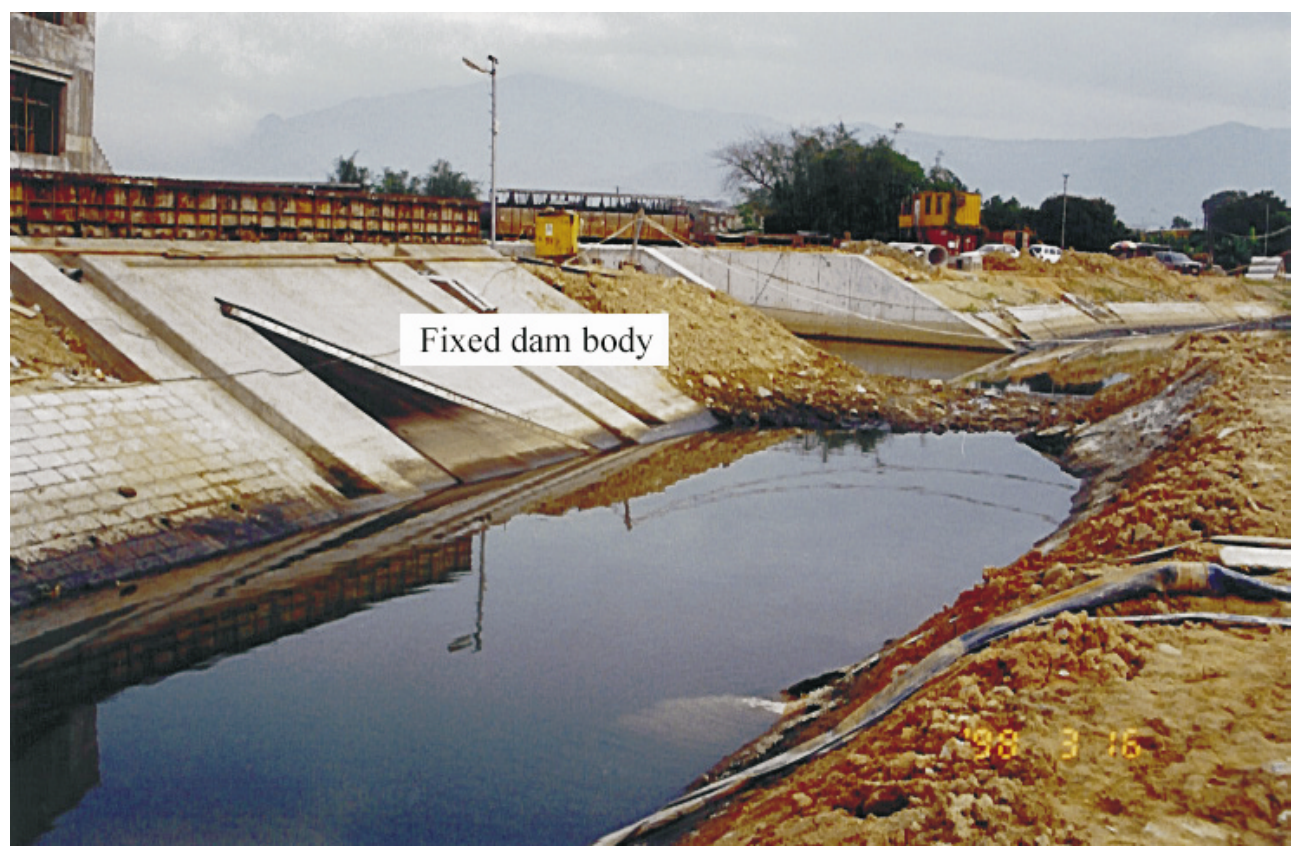

the inflation of the dam, but may also damage it. Thus, desilting traps are essential to the proper functioning of the dam. To facilitate regular desilting, vehicular access is usually provided from the riverbank to the bottom of the desilting trap.

\section{Dam body installation}

The rubber dam body is a membrane of rubberized fabric, which is composed of layers of synthetic rubber and layers of synthetic fiber reinforcement that are firmly bonded together by vulcanization. When a rubber bladder is manufactured, quality control is maintained throughout the processes of rubberizing, putting together and gluing. Unevenness or local imperfections can lead to bladder breakage. With a large bladder, truck or container transportation may pose restrictions on packing dimensions. Therefore, the adhesion of the bladder has to be carried out on site. Special attention should be given to quality management, since conditions (e.g., dust and humidity) at the dam site may adversely affect the adhesion process.

Before the transportation from the factory to the dam site, the rubber bladder is wound into roll and carefully packaged to avoid any deformation and damage. The bladder and its related parts should be protected against corrosion, mechanical damage, and deterioration during transportation and onsite storage before installation.

The installation of the rubber bladder is simple and can be finished within a short period. Easy and quick installation is one of the advantages of rubber dams compared with other hydraulic structures, such as steel gates, concrete dam, and earth and stone dams. For an experienced crew, the installation of the rubber bladder can be completed in one day. Table 1 shows the installation sequence and time duration of Dam No. TKL 12, Hong Kong, China. The installation crew comprised four members (a supervising engineer from the manufacturer, an interpreter, and two labourers).

\section{Construction costs}

Compared with steel gates, the rubber dam becomes more cost-effective with the increase in the length of its span(s). Steel gates are expensive and require intermediate structures (such as concrete piers) that collect debris during floods. Although flashboards are inexpensive to construct, they are unreliable and expensive from an operation and maintenance point of view. The rubber dam is almost maintenance free compared with a steel gate, which requires periodic maintenance such as repairs to the lifting mechanisms, sandblasting, and painting. In the case of raising the crest of an existing dam, the rubber dam is much cheaper to install than any of the various types of steel gates; in fact, given the design of an existing structure, many types of steel gates may be non-viable alternatives. Furthermore, the increased water storage capacity for additional power generation and water supply can result in rapid payback of the construction cost of the rubber dam.

\section{Operation mechanisms}

\section{Inflation, deflation, and safety systems}

Inflation and deflation devices are installed in the control room. An air blower or water pump and ancillary devices such as valves are used to inflate the air- or water-filled dam respectively. There are three types of deflation systems: bucket, float, and electrical. For the bucket type, water flows into the bucket causing it to fall when the upstream water rises to the deflation level. As it falls, the exhaust valve is opened, deflating the dam body. For the electrical type, a sensor monitors water level. The exhaust valve is opened automatically when the upstream water level reaches the deflation level. For the float type, a float fluctuates up and down with the water level. The outlet valve is opened automatically when the deflation level is reached. 
Table 1. Installation sequence and time duration of rubber dam No. TKL 12.

\begin{tabular}{|c|c|c|c|}
\hline Date and time & Duration $(\mathrm{h})$ & Sequence & Work \\
\hline \multirow[t]{3}{*}{20 January 1997, 09:00-12:30 } & 3.5 & 1 & Cleaning of dam foundation \\
\hline & & 2 & Checking for possible mismatch of the anchor bolts and anchor plates \\
\hline & & 3 & Application of sealant along the line of anchor bolts \\
\hline \multirow[t]{3}{*}{20 January $1997,14: 00-17: 00$} & 3 & 4 & Placing of rubber dam body over dam foundation \\
\hline & & 5 & Drilling of holes on dam body for anchorage (bottom layer; river bed) \\
\hline & & 6 & Marking the exact position of the pipe opening (bottom layer; river bed) \\
\hline \multirow[t]{2}{*}{21 January $1997,14: 00-17: 00$} & 3 & 9 & Installation of pipe flanges for the air inlet and release system \\
\hline & & 10 & Drilling of holes on dam body for anchorage (top layer; river bed) \\
\hline \multirow[t]{2}{*}{22 January $1997,10: 00-12: 00$} & 2 & 11 & Drilling of holes on dam body for anchorage (bottom layer; river bank) \\
\hline & & 12 & Trimming of dam body \\
\hline 22 January $1997,13: 30-16: 00$ & 2.5 & 13 & Clamping of dam body \\
\hline
\end{tabular}

Fig. 2. Automatic control mechanism.

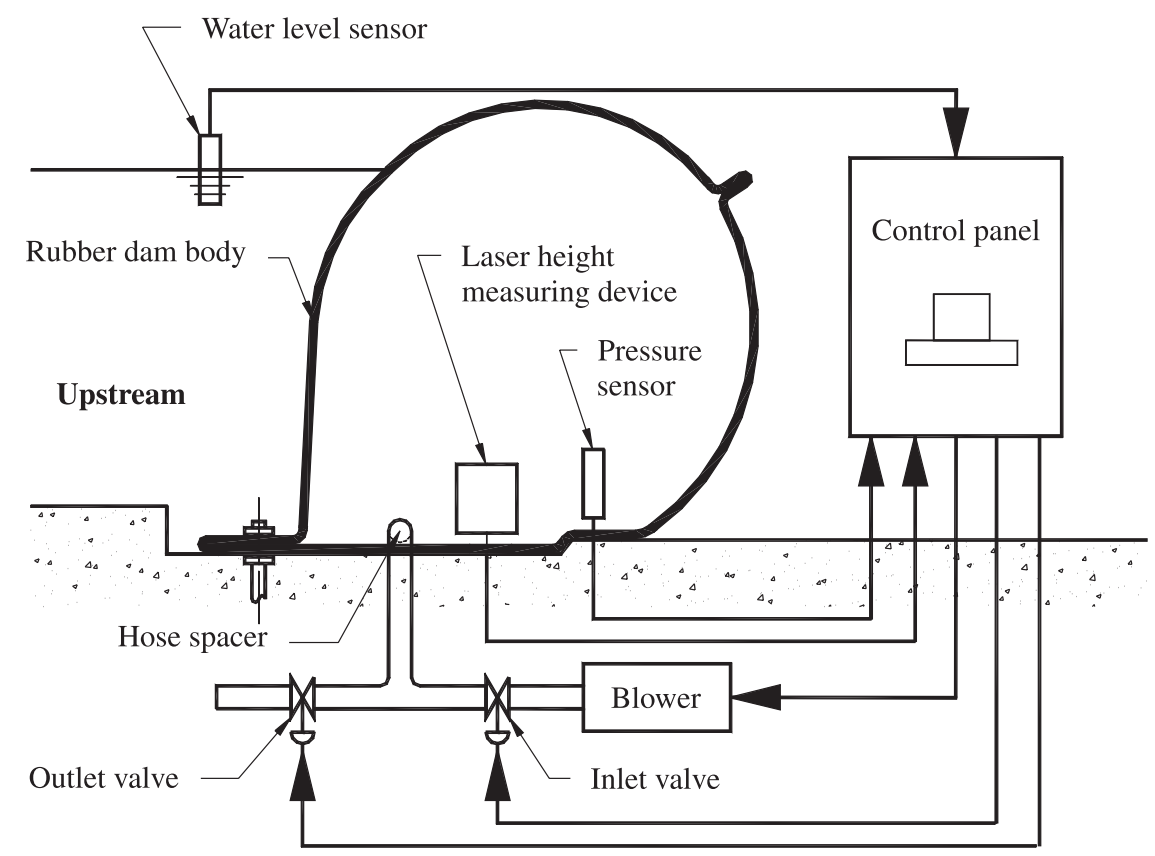

An air blow-off tank can be used as a safety device for the air-filled dam. It ensures that air is released from the dam body when the principal deflation mechanism malfunctions or the inner air pressure exceeds the maximum design pressure. For a water-filled dam, a siphon pipe can be used for safety purposes. It operates when the principal deflation mechanism fails or when inner water pressure rises above the maximum operating pressure.

\section{Monitoring of inner pressure and dam height}

A pressure sensor (Fig. 2) is used to monitor the inner pressure of the dam body. The inlet of air/water to the dam body is cut off automatically when inner pressure reaches the preset level. This prevents damage to the dam body due to excessive pressure. The inner pressure of an air-filled dam can be maintained at a constant value even though the dam is installed in a variable exterior environment.

A laser height measuring device (Fig. 2) can be installed inside the dam body to continuously measure its height when inflating or deflating.

\section{Inflation and deflation procedures}

Based on Bridgestone (1994) and experiences in Hong Kong, the following procedures are recommended for the inflation or deflation of an air-filled dam. The procedures for inflating and deflating a water-filled dam are similar to those for an air-filled dam.

\section{Inflation}

1. Inspect the upstream side, ensuring that neither people nor property will be adversely affected by raising the upstream water level.

2. Remove debris (especially sharp objects) adjacent to the rubber dam.

3. Close the air exhaust valve.

4. Open the air supply valve.

5. Start the air compressor.

6. Monitor the air pressure gauge while inflating the dam. Adjust the air pressure according to the headwater level. If the headwater level is less than $1 / 2$ of the dam height, the air pressure should be approximately $60 \%$ of the de- 
sign pressure. The air pressure should increase in proportion to the headwater level. Increase the air pressure to the design level after the headwater reaches the design level. Then turn off the air compressor and close the air supply valve.

\section{Deflation}

1. Inspect the downstream side, ensuring that neither people nor property will be adversely affected by raising the downstream water level.

2. Make sure the downstream side of the dam foundation is free of sharp objects and other obstructions that may damage the dam body during deflation.

3. Open the drainpipe to drain the condensed water.

4. Open the air exhaust valve to deflate the dam.

\section{Inflation/deflation time}

Inflation time is a function of three main factors: the inner volume of the dam body, the external pressure acting on the dam body, and the capacity of the air compressor or water pump. According to Bridgestone (1994), compressors ranging from 1.9 to $15 \mathrm{~kW}$ have been used. A $1.9 \mathrm{~kW}$ air compressor that produces air at a rate of $3.0 \mathrm{~m}^{3} / \mathrm{s}$ can inflate a $0.8 \mathrm{~m}$ high and $10 \mathrm{~m}$ long dam in $3 \mathrm{~min}$, while two $15 \mathrm{~kW}$ compressors can inflate a $2.6 \mathrm{~m}$ high and $60 \mathrm{~m}$ long dam in about $65 \mathrm{~min}$. Deflation time is a function of the external pressure, the volume of the dam body, and the number of exhaust pipes. The dam deflates more quickly when there is a head of water acting on the dam body.

\section{Inspection gallery}

Some large rubber dams include an inspection gallery (Fig. 3), which permits regular inspection inside the dam body. Through this gallery, inspectors can identify problems earlier and take appropriate preventive and corrective actions. The provision of such a gallery improves the safety and security of the dam. The $1.1 \mathrm{~m}$ high and $147.7 \mathrm{~m}$ wide rubber dam on Naruse River, Miyagi Prefecture, Japan, is provided with such an inspection gallery. The gallery houses instruments for the observation of $(i)$ dam shape, (ii) dam vibration, (iii) dam tension, (iv) dam abrasion, ( $v$ ) river sediment flow, and (vi) river flow condition when deflated (Bridgestone 1992).

\section{Management practices in Hong Kong}

Rubber dams were introduced to Hong Kong in the 1960s. To date, a total of 20 rubber dams have been installed in Hong Kong, among which 15 by the Agriculture and Fisheries Department (AFD), 3 by the Water Supplies Department (WSD), and 2 by the Drainage Services Department (DSD). These dams are used for irrigation, pollution abatement, environment improvement, flood mitigation, and water supply. Tam (1998) provides some comparative information of these dams.

\section{Hand-over test, operation manual, and spare parts}

In Hong Kong, when the construction of a rubber dam is completed, a hand-over inspection and completion test is conducted before the dam is taken over by the personnel re-
Fig. 3. Inspection gallery.

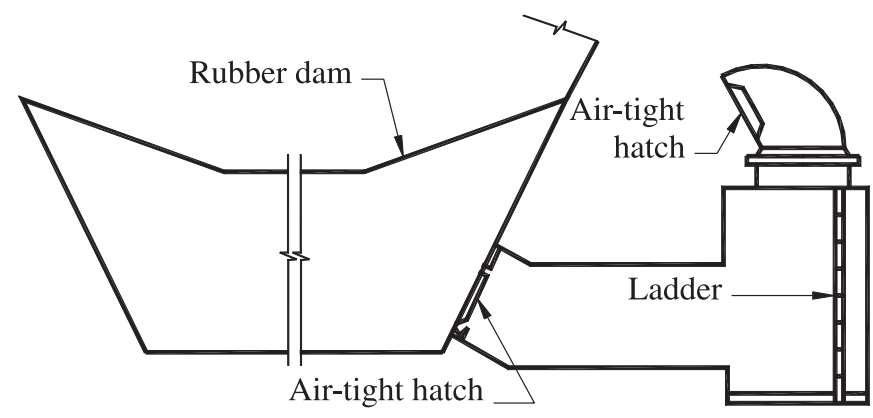

sponsible for future daily operation and maintenance. This ensures that construction and installation have been properly carried out and that the dam will function properly. The contractor usually provides an instruction manual, which gives a detailed description of the whole rubber dam system, including the dam body, inflation/deflation procedures, power supply system, and other accessories. Personnel responsible for the operation, maintenance, and repair of the dam are required to use this manual in conducting their duties.

To facilitate maintenance and repair, it is advisable to have the supplier provide a set of repair kits and sufficient key spare parts to ensure satisfactory performance of the dam. A price list including the names of manufacturers of all necessary spare parts and tools for repair should also be provided for future reference. It is recognized that the rubber dam is a patented product. Therefore, the lack of repair tools and spare parts can cause great difficulty in repairing malfunctioning equipment or the dam body itself.

\section{Operation mechanism}

Rubber dams in Hong Kong have an electrical inflation/deflation system. Hydrostatic level sensors are erected both upstream and downstream of the dam. The sensors detect the water levels and transmit signals to the control unit, which is a programmable logic controller (PLC). The control unit determines whether the dam should be inflated, deflated, or kept at the present running mode. When the water level reaches a dangerous level, the deflation device is automatically triggered to deflate the dam and thus to mitigate flood.

Signals are also transmitted to the control centers in $\mathrm{Ha}$ Tsuen Pumping Station or Yuen Long Sewerage Treatment Plant. Emergency operation teams stationed there will monitor the situation at each rubber dam and take appropriate action as required. In the case of an emergency, such as the PLC not functioning properly, the control center can send signals to the dam control room to regulate its function. In the event that this step also fails, an emergency team will go to the dam site to carry out the necessary operations.

Dams installed by the Drainage Services Department can re-inflate automatically when the upstream water level drops to the designed inflation point. Although the Agriculture and Fisheries Department dams can automatically deflate during heavy rainstorms according to the predetermined upstream water level, they cannot re-inflate automatically. The dams are manually inflated, for example, when the rainstorms are over. 
Fig. 4. Pressure record of rubber dam No. YLN 189.

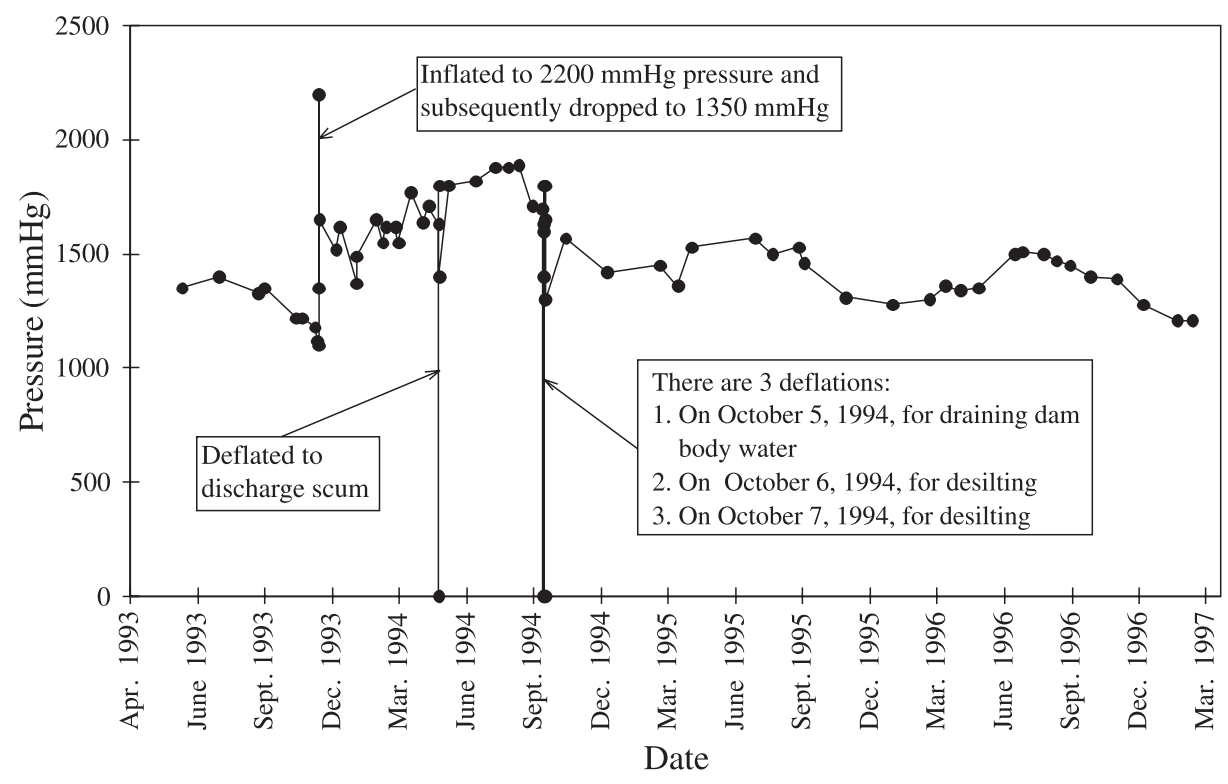

\section{Operation record}

To monitor the performance of rubber dams and for future reference as well, important operation data have been recorded and stored in the Ha Tusen Pumping Station or Yuen Long Sewerage Treatment Plant. These data include inner air pressure of the dam body, upstream/downstream water levels, times of inflation and deflation, dates, and reasons for such operations. These data can be used by the operation team to investigate the reasons for a particular inflation or deflation and report to their senior management or to the public, if requested. This information is also valuable for the study of the river's hydrology, including the pattern of water level changes throughout the year. Figure 4 shows the pressure record of Dam No. YLN 189 from June 1993 to March 1997.

The Hong Kong Observatory will announce rainfall and flood warnings when the intensity of rainfall collected in the previous 2-h period exceeds $50 \mathrm{~mm} / \mathrm{h}$. In periods of excessive precipitation, river water levels are high. Some dams must be deflated to allow the passage of flood flows, thus avoiding flooding to adjacent areas. The AFD's rubber dam deflation record shows that most deflations occur during the wet season, especially in July and August. The average annual deflation (or inflation) frequency for rubber dams in Hong Kong is about 6 times per dam.

\section{Safety considerations}

When the rubber dam is inflated/deflated, water levels change suddenly and may create a hazard to adjacent people and properties. Information on dam inflation and deflation is provided in advance to the people concerned so that they can take proper protection measures. In addition, warning and notification signs are erected along riverbanks adjacent to rubber dams to draw attention to the danger of sudden water level change.

The installation of a rubber dam across a river may sometimes tempt people to use it as a footbridge. This not only may damage the dam but also pose a danger to the trespass- ers. Notices are posted as reminders not to use the dam to cross the river.

\section{Coordinated operation in the future}

Successful management and public support encourage a new plan to install more rubber dams in river training projects in Hong Kong. For example, there are many potential sites where rubber dams can be installed to relieve flood at locations such as the lower reaches of the Indus River. Furthermore, since they have been proven to be more useful and reliable, rubber dams will gradually replace existing concrete irrigation weirs in the North and Yuen Long Districts. In addition, future dams will be multipurpose, combining flood control, irrigation, water supply, channel maintenance, and environmental improvement to achieve maximum benefits.

At present, rubber dams in Hong Kong are under the separate control of three departments (AFD, DSD, and WSD). In the long term, when more watercourses become engineered, there will be a need for the coordinated operation of rubber dams to meet various demands.

\section{Operation example: Tin Shui Wai rubber dam}

Until about 70 years ago, the area that now comprises the Tin Shui Wai new town, New Territories, Hong Kong, was a shallow bay. During development of the new town, extensive land reclamation was carried out, greatly reducing the flood storage capacity in the catchment and increasing the flood risk in low-lying flood-prone areas around the town. Streams through the town tend to be tidal and are prone to severe silting from muddy water in the shallow bay. Furthermore, these streams are heavily polluted by pig wastes and effluent from farms, villages, and towns in the upstream. In addition, the main catchment drainage channel (MCDC) is an important landscape and recreation feature in the town. However, it is broad (about $60 \mathrm{~m}$ wide) and could create a harsh feature in an otherwise pleasant environment. For mitigating 
Fig. 5. Tin Shui Wai Rubber Dam.

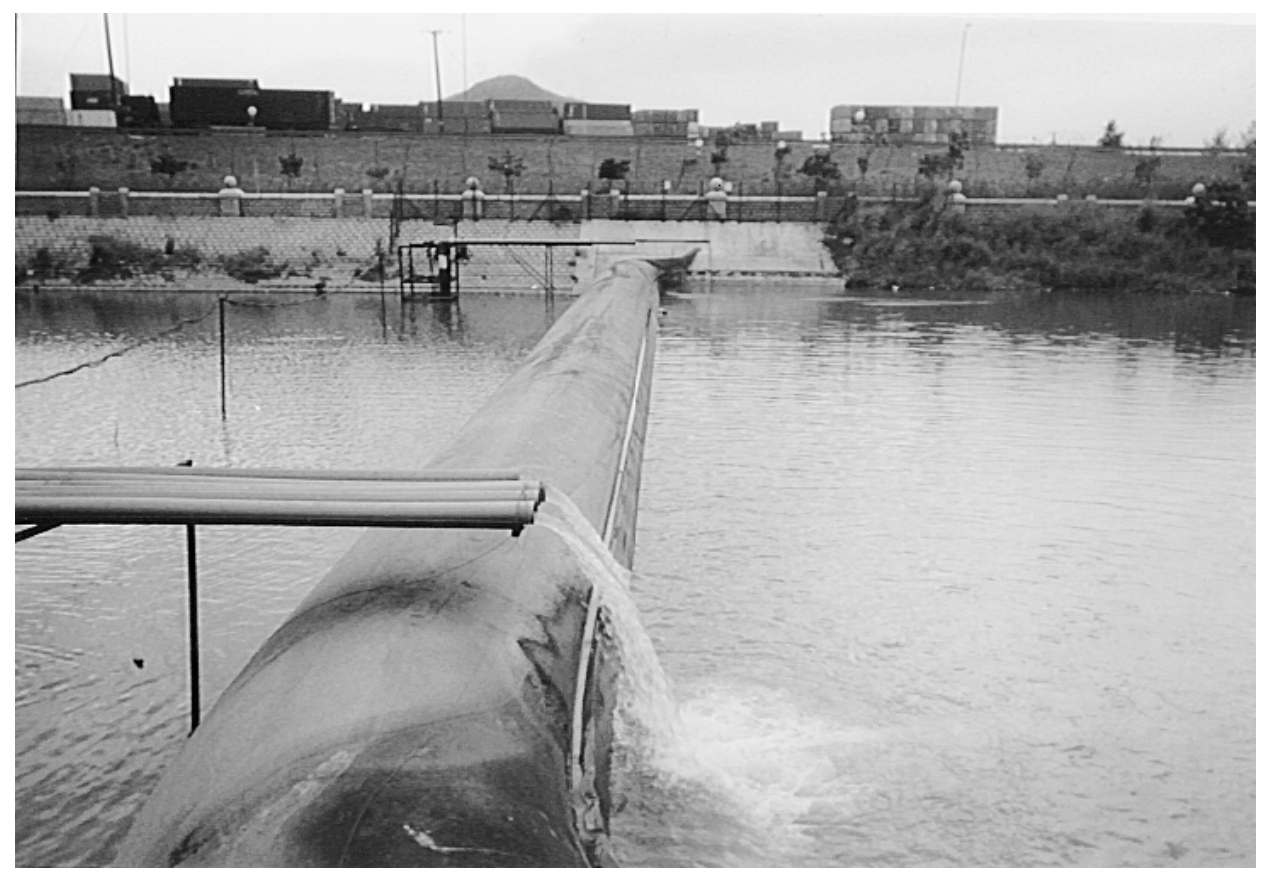

flood and improving the environment, a rubber dam (Fig. 5) with a bypass was installed across the MCDC in 1991.

The dam serves three main functions: $(i)$ to retain amenity water in the MCDC at a level of +2.0 m P.D. (principal datum); (ii) to allow the smooth passage of storm water without flooding the new town or exacerbating flooding in the low-lying areas; and (iii) to replace amenity water by partially deflating the dam when water becomes polluted or its quality deteriorates during prolonged dry spells. This operation ensures that water is maintained at a "passive amenity value" - visually pleasing and without offensive odor.

Operation of the dam is controlled by water level sensors and a preset logic. It deflates when the upstream water level is more than $2.5 \mathrm{~m}$ P.D., and higher than the downstream level. The dam also deflates when the upstream water level reaches $3.0 \mathrm{~m}$ P.D., irrespective of the downstream level. The dam remains in the deflated mode until the upstream water level drops below $2.0 \mathrm{~m}$ P.D., at which point the air blower starts and re-inflates the dam.

There is also a bypass to the dam. The bypass includes three penstocks, two of which can be manually adjusted to vary the level of amenity water, while the third one is normally closed but can be opened to drain the water as an alternative to deflating the dam.

\section{Preventive maintenance}

Innovative materials and designs have been applied to rubber dams to increase their life span and enhance their performance. However, the life and performance of a rubber dam project are dependent on many external factors. Tam and Zhang (1999) have discussed various factors that can negatively affect and even damage the rubber dam. It is concluded that rubber dams are most vulnerable to two types of damages, due respectively to $(i)$ vandalism and (ii) floodborne debris, especially sharp objects. The objectives of pre- ventive maintenance are to increase the dam's reliability and reduce the time when the dam is inoperable.

\section{Periodic inspection and routine maintenance}

Based on the management practice of rubber dams in Hong Kong, an operation and maintenance check list (Fig. 6) is developed for this paper. Inspection and maintenance are carried out periodically. These include mainly $(i)$ inspecting the dam body and surrounding environment to identify if there is any presence of potential damages, such as punctures and cuts; (ii) removing silt and debris from both upstream and downstream of the dam; and (iii) keeping the chamber that houses the level sensors and associated piping systems clean and thus ensuring that the electrical and mechanical control equipment receives true information. Table 2 shows the components to be inspected, contents of inspection, and inspection frequency.

The need for maintenance of rubber dams is minimal. They do not corrode or require painting. Table 3 shows the maintenance actions for Dam No. YLN 189 from June 1993 to September 1995. The average maintenance time was about $3 \mathrm{~h}$ in each inspection. The total maintenance time $(129 \mathrm{~h}$ ) was only about $0.6 \%$ of the total operation time (approximately $19992 \mathrm{~h}$ ). Table 4 provides a comparison of the construction, operation, and maintenance costs of the Yuen Long Inflatable Dam.

\section{Sediment removal}

Sediment moving at high velocities in a hyper-sedimentladen river has a scouring effect on the dam body. Since rubber is less susceptible to scour than concrete, this does not pose a major problem to the dam body. In addition, if the sediment problem is endemic to a particular channel, an abrasion-resistant layer can be incorporated onto the outer layer of the dam body. However, sediment accumulation behind a rubber dam may affect the normal operation of the 
Fig. 6. Rubber dam operation and maintenance check list.

\section{Operation and Maintenance Check List}

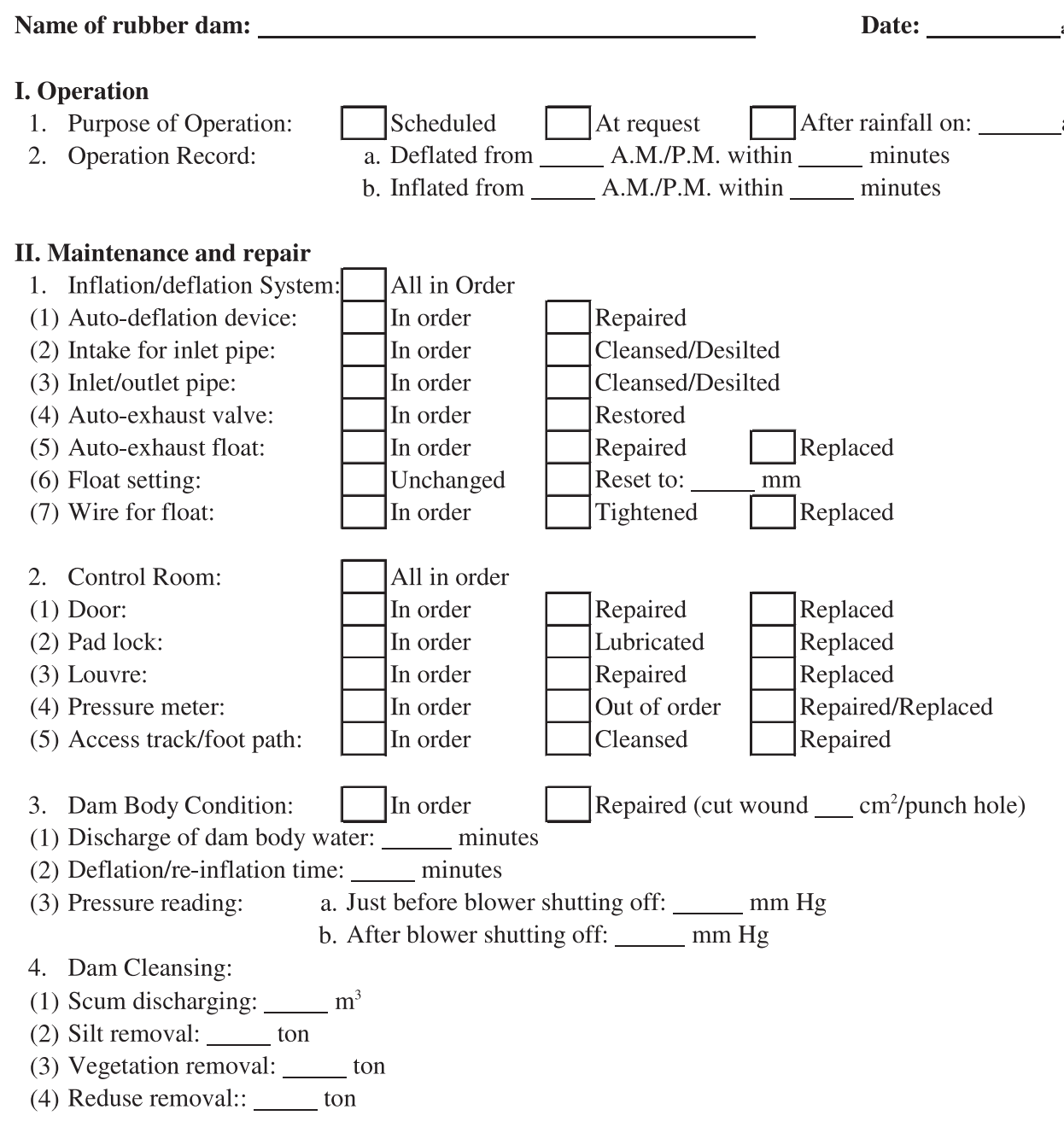

Reported by:

Checked by:
Approved by: dam. For example, a large amount of sediment buildup on a deflated rubber dam may make it difficult to inflate it to the normal height. Silt and debris can be removed periodically using manual or mechanical tools.

Another way to solve sediment problem is to flush the sediment downstream by deflating the dam. In 1985, Sumitomo used a $5 \mathrm{~m}$ high and $10 \mathrm{~m}$ wide experiment dam to test the sediment removal capability of rubber dams through flushing. $160 \mathrm{~m}^{3}$ of silt, sand, and rubble were piled to $3 \mathrm{~m}$ high upstream of the dam. Within the deflation time of $60 \mathrm{~min}$, the material piled up was removed as a result of the flushing effect. An inflation test with silt deposited on the deflated rubber dam was also carried out. Test results indicated that if the depth of the deposit does not exceed $20 \%$ of the maximum height of the dam, the dam can be raised to its normal height when subject to the normal inflation pressure (Sumitomo 1985). It is acceptable to exceed the normal operating pressure by up to 1.5 times to lift a sedimentcovered dam and then reduce the pressure once the sediment has been cleared (Bridgestone 1994). In the case of a large amount of sediment still remain after initial inflation, it is advisable to deflate the dam again after a water head has developed.

\section{Prevention of vandalism}

Vandalism is a major concern affecting the application of rubber dams. The most common types of vandalism are bullet holes and knife cuts. Bridgestone had endorsed bullet damage tests. Caliber rifles were fired at a $12.5 \mathrm{~mm}$ thick sample piece of their rubber dams from distances of 5-30 m. Most of the bullets passed through the sample. However, the bullet holes were much smaller than the projectiles due to the elasticity of rubber. A rubber dam does not burst like a balloon as a result of gun shots because of its reinforced fabric body. Knife cuts are a big concern because the area damaged in this way is usually larger and more difficult to repair than bullet holes.

Ceramic chips, steel mesh, and Kelvar have been used to armor, harden, and strengthen the dam body. For example, because ceramic chips are harder than steel, a knife cannot 
Table 2. Periodic inspection of rubber dams.

\begin{tabular}{|c|c|c|}
\hline Components & Contents of inspection & Frequency \\
\hline Dam body & Whether there is any signs of damages or fatigue & Yearly \\
\hline Anchoring system & Whether there is any sign of deformation of bolts and nuts or loosing & Yearly \\
\hline Rubber dam surrounding areas & Whether there is accumulation of debris on top of or adjacent to the dam & Bimonthly \\
\hline Water level sensor & Whether the sensor screen is blocked & Yearly \\
\hline Silt trap & Whether there is accumulation of silt, rubbish, and other objects & Monthly \\
\hline \multirow[t]{2}{*}{ Inlet structure } & Whether there is siltation blocking the screen at inlet box & Monthly \\
\hline & Whether there is siltation in the culvert & Yearly \\
\hline \multirow[t]{2}{*}{ Outlet structure } & Whether the flap gate at outlet box functions properly & Yearly \\
\hline & Whether there is siltation in the culvert & Yearly \\
\hline Control room & Whether the electric and mechanic equipment functions properly & Monthly \\
\hline
\end{tabular}

cut or break them. Therefore a dam can be effectively protected from knife cuts by coating with a sufficient density of ceramic chips. Furthermore, the bond strength between the outer ceramic chips and the inner dam body layer is greater than the strength of the rubber itself, indicating that rubber tears before the adhesive bonding gives way. However, a coating of ceramic chips is not an effective countermeasure against bullet damage. Self-healing rubber has been used to prevent the loss of air from bullet holes. In addition, since the rate of air escape from bullet holes is slow at low inner pressure, an automatic air supply mechanism can be incorporated into a rubber dam. Upon detecting a drop of inner pressure below a preset trigger level, an air pressure sensor will start the air compressor to pump air into the dam. Once the inner pressure reaches the design operating level, the compressor turns off automatically.

Furthermore, a security fencing system can be used to prevent unauthorized people from entering the dam area, and a closed circuit television (CCTV) can be installed to deter vandals and to visually monitor dam operation as well. For example, $2.5 \mathrm{~m}$ high fences were erected in the Yeun Long Nullah Inflatable Dam in Hong Kong. CCTV systems have been provided for all DSD dams and this practice is increasingly used on other rubber dam sites.

\section{Inspection and removal of sharp objects}

Another major concern is that sharp objects carried down by fast-moving flow can puncture the upstream side of the dam body. Large moving objects such as rubble and stones also have a damaging impact on the dam body. To reduce the risk of damage by sharp objects during inflation and deflation, removal of silt and debris is carried out regularly on both the upstream and downstream sides of the dam. A resilient cushion can be incorporated onto the inner layer of the dam body to reduce the impacts of moving objects. In addition, trapping troughs can be constructed across the channel to trap sharp objects and debris and thus to keep potential damage to the minimum.

\section{Rubber dams in cold area}

Rubber dams are operable in very cold weather, and airfilled dams perform better than water-filled ones in such conditions. For example, two rubber dams (the Rainbow
Table 3. Maintenance actions at dam No. YLN 189.

\begin{tabular}{ll}
\hline Item & No. of times* \\
\hline Inspection & 43 \\
Topping up of air pressure & 5 \\
Removal of drainage water & 1 \\
Desilting & 2 \\
Discharge of scum & 1 \\
\hline
\end{tabular}

*Number of times from June 1993 to September 1995.

Dam and the Broadwater Dam) on the Missouri River, Montana, are in operation, where the temperature may be as low as $-40^{\circ} \mathrm{C}$. In a river prone to icing, upstream water surface adjacent to a rubber dam should be kept unfrozen to protect its body from being damaged by the great pressure of a large-area ice block. In case such a large block is formed, it should be broken into small pieces using manual or mechanical tools. Small pieces can pass over the dam to the downstream. The rubber dam absorbs impacts from drift ice by its capacity to undergo deformation during ice passage and regains its shape thereafter. The rubber dam at Highgate Falls, Vermont, is subject to heavy ice passage. In Canada, hinged steel plates are often used to protect the dam from ice damage.

\section{Corrective maintenance}

Although various preventive measures have been taken to reduce the incidence and extent of damage to rubber dams, these cannot be completely avoided. Corrective maintenance is performed to restore malfunctioning units to a satisfactory and safe condition within the shortest possible time.

Damage to the dam body can be classified into four types: (i) small puncture (e.g., bullet hole), (ii) surface damage, (iii) small area damage, and (iv) large area damage. The repair of small cuts/punctures would normally take half to one day. However, for a large area damage a longer repair period may be needed. For example, 10 days were spent to repair the damage caused to Dam No. YLN 189 in November 1997. Figure 7 shows the repair schedule of this dam. Table 5 provides a record of the AFD concerning puncture repairs of their dams. Repair techniques are discussed in the following sections and are shown in Fig. 8. 
Table 4. Construction, operation, and maintenance costs for Yuen Long inflatable dam.

\begin{tabular}{lrr}
\hline & \multicolumn{1}{l}{ Cost } \\
\cline { 2 - 3 } Description & (HK\$) & \multicolumn{1}{c}{ (US\$) } \\
\hline Construction cost (not including foundation cost) & 13071600 & 1675847 \\
Manufacture and supply of rubber dam body & 7614000 & 976154 \\
Fixing equipment & 1500000 & 192308 \\
Pipes & 147600 & 18923 \\
Operating equipment & 2100000 & 269231 \\
Installation, test, and commission & 1350000 & 173077 \\
Independent checking of design and works & 360000 & 46154 \\
Annual operation and maintenance costs & 130000 & 16667 \\
Electrical and mechanical aspects & 100000 & 12821 \\
Civil aspects & 30000 & 3846 \\
\hline
\end{tabular}

Fig. 7. Repair schedule of dam No. YLN 189.

\begin{tabular}{|c|c|c|c|c|c|c|c|c|c|c|}
\hline \multirow{2}{*}{ Description of Process } & \multicolumn{10}{|c|}{ Duration (day) } \\
\hline & 1 & 2 & 3 & 4 & 5 & & 7 & 8 & 9 & 10 \\
\hline $\begin{array}{l}\text { 1. Preparation: } \\
\text { (1) Flipping rubber dam body to expose damaged are } \\
\text { (2) Elevating damaged portion by chain link block }\end{array}$ & & & & & & & & & & \\
\hline $\begin{array}{l}\text { 2. Water diversion: } \\
\text { (1) Setting up sand bags } \\
\text { (2) Loosening damping system }\end{array}$ & & & & & & & & & & \\
\hline 3. Repair & & & & & & & & & & \\
\hline 4. Removal of sand bags & & & & & & & & & & \\
\hline 5. Leakage test & & & & & & & & & & \\
\hline 6. Patching for protection & & & & & & & & & & \\
\hline
\end{tabular}

\section{Small puncture (bullet hole)}

The air pressure record can be used to analyze whether or not a dam is leaking. A suspected hole in the dam body can be found in two ways. The submerged portion can be checked for air bubbles coming from the dam body, while the portion above water can be coated with soapy water and inspected for bubbles caused by air leakage.

The simple method to repair automobile tires by inserting plugs can be deployed to repair small punctures (e.g., bullet holes) to a rubber dam. One advantage of this technique is that it does not require the damaged area to be dry. Therefore, dam operation is not interrupted during repair. The following procedures have been used in the repair of small puncture holes:

1. Remove the object that causes the puncture from the dam body. It is better to keep the damaged area clean and dry.
2. Insert a needle covered with cement into the puncture hole several times so that cement would fill in the hole.

3. Insert sealing plug into the puncture hole.

4. Test for air leakage by spreading soapy water over the repaired area. The repair is successful if no bubbles appear.

5. Cut off the end of the sealing plug.

\section{Surface damage}

To repair surface damage, the following simple procedures are adopted:

1. Cut off the outer surface of the damaged area.

2. Fill self-vulcanizing rubber into the damaged area after cleaning and drying.

3. Smooth outer surface by removing protruding rubber materials. 
Table 5. Puncture repair record (up to November 1997).

\begin{tabular}{llll}
\hline $\begin{array}{l}\text { Dam No. } \\
\text { (year installed) }\end{array}$ & $\begin{array}{l}\text { Number of } \\
\text { damages }\end{array}$ & Dates of repair & $\begin{array}{l}\text { Repair duration } \\
\text { (day) }\end{array}$ \\
\hline BR9 (1991) & 4 & 23 June 1993 & 0.5 \\
& & 13 October 1993 & 0.5 \\
& 20 October 1993 & 0.5 \\
21 December 1994 & 0.5 \\
BR11 (1991) & 2 & 12 July 1993 & 0.5 \\
BR16 (1992) & 2 & 20 July 1993 & 0.5 \\
YLN65 (1992) & 1 & 5 September 1996 & 1 \\
YLN 189 (1992) & 1 & 11 December 1993 & 2 \\
BR8 (1991) & - & 12 December 1993 & \\
BR10 (1991) & - & - & 10 \\
TKL6 (1997) & - & - & - \\
TKL11 (1997) & - & - & - \\
TKL12 (1997) & - & - & - \\
TKL13 (1997) & - & - & - \\
YLN117 (1992) & - & - & -
\end{tabular}

Fig. 8. Repair techniques for different types of damage to the rubber dam body.
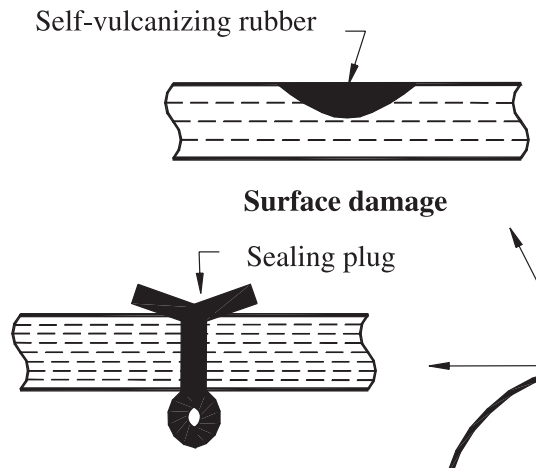

Bullet hole

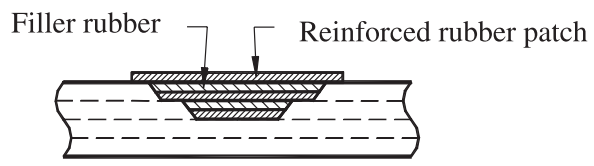

Small area damage

Filler rubber $] \quad[$ Reinforced rubber patch

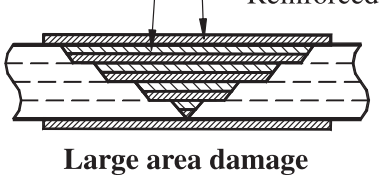

Large area damage

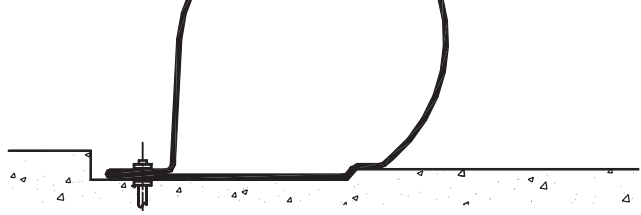

\section{Small-area damage}

For small-area damage, the following procedures are adopted:

1. Cut off the outer rubber around the damaged area at approximately $45^{\circ}$.

2. Buff the cut surface, then clean and dry it.

3. Apply cement two times to the cut surface, the second coat applied after the first coat has dried.

4. Apply cement to a piece or several pieces of filler rubber and then patch the filler rubber onto the cut surface after the cement has dried.

5. Apply cement to a piece of reinforced fabric and patch it onto the filler rubber after the cement dries.
6. Level the applied piece of reinforced fabric by rolling it with a grinder.

7. Repeat steps 4, 5, and 6 until the last piece of reinforced fabric covers the outer surface of the dam body.

8. Patch the outer surface of the damaged area with a piece of reinforced fabric.

9. Carry out an air leakage test.

\section{Large-area damage}

The first 8 steps of the technique for repairing a large-area damage are similar to those for a small-area damage, plus the following two steps: 
9. Patch the inner side of the damaged area with a piece of reinforced fabric.

10. Carry out an air leakage test.

\section{Conclusions}

Based on literature review, interviews/correspondence with professionals and practitioners, and case studies of the 20 rubber dams in Hong Kong, this paper discusses the various issues concerning the construction, operation, maintenance, and repair of rubber dams.

The rubber dam has been put into a wide scope of application (irrigation, water supply, power generation, flood control, environmental improvement, and recreation) due to its structural simplicity, being inflatable and deflatable, and proven reliability. The air-filled rubber dams are used more often than the water-filled ones for a number of reasons.

In the selection of a suitable dam site, geological, geomorphic, hydrologic, meteorological, and hydraulic conditions should be considered. The dam site should be in a straight section where river flow is smooth and riverbed and bank slopes are stable. It is better to carry out the construction of civil works related to the rubber dam in a dry season. The sequence and program of construction works should be carefully planned and an appropriate water diversion measure should be taken.

Compared with steel gates, the rubber dam becomes more cost-effective with the increase of the length of its span(s). The operation of rubber dams is easy and the operation and maintenance costs are minimal because of their simple structure and innovative inflation and deflation mechanisms. Nevertheless, proper operation procedures should be adopted to ensure safe operation.

Rubber dams are subject to external damages, especially vandalism and punctures by fast-flowing sharp objects. Therefore, both preventive and corrective maintenance measures should be carried out to keep rubber dams in effective operational condition as long as possible. Repair techniques for four types of damages to the dam body have been presented.

\section{References}

Bridgestone Corporation. 1992. Naruse River tidal barrier rubber dam. Tokyo, Japan.

Bridgestone Corporation. 1994. Questions and answers about the Bridgestone rubber dam. Tokyo, Japan.

Bridgestone Corporation. 1997. Rubber dam: inflatable rubber weir. Tokyo, Japan.

Hamed, G.R. 1992. Materials and compounds. In Engineering with rubber, how to design rubber components. Edited by A.N. Gent. Carl Hanser Verlag, Munich, Germany.

Kahl, T., and Ruell, S. 1989. Flashboard alternatives including rubber dams. Proceedings of Waterpower '89, Niagara Falls, New York, N.Y., pp. 447-456.

Lu, W.H. 1988. Rubber dams. China Agricultural Science and Technology Press, Beijing, China (in Chinese).

Markus, M.R., Thompson, C.A., and Ulukaya, M. 1995. Aquifer recharge enhanced with rubber dam installations. Water Engineering and Management, 142(1): 37-40.

Moorthy, C.M.D., Reddy, J.N., and Plaut, R.H. 1995. Threedimensional vibrations of inflatable dams. In Thin-walled structures. Elsevier Science, Ltd., Amsterdam, The Netherlands. Vol. 21, pp. 291-306.

Plaut, R.H., Liapis, S.I., and Telionis, D.P. 1998. When the levee inflates. Civil Engineering, January, pp. 62-64.

Sumitomo Electric Industries Ltd. 1985. Technical description of Sumigate: inflatable rubber dams. Osaka, Japan.

Sumitomo Electric Industries Ltd. 1990. Inflated ideas. New Civil Engineering, September, pp. 34-38.

Sumitomo Electric Europe SA. 1991-1992. The inflatable rubber dam: 30 years on. Kensington Publication Limited, London, U.K.

Sumitomo Electric Industries Ltd. 1997. Pioneering rubber gate technology: Sumigate. Osaka, Japan.

Tam, P.W.M. 1998. Use of inflatable dams as agricultural weirs in Hong Kong. Journal of Hydraulic Engineering, 124(12): 12151226.

Tam, P.W.M., and Zhang, X.Q. 1999. Management of rubber dams in Hong Kong. Canadian Journal of Civil Engineering, 26: 123-134. 
Copyright $\odot 2003$ EBSCO Publishing 